\title{
Lymphatic endothelial cells attenuate inflammation via suppression of dendritic cell maturation
}

\author{
Ailsa J. Christiansen ${ }^{1}$, Lothar C. Dieterich ${ }^{1}$, Isabel Ohs ${ }^{1}$, Samia B. Bachmann ${ }^{1}$, \\ Roberta Bianchi ${ }^{1}$, Steven T. Proulx ${ }^{1}$, Maija Hollmén ${ }^{1}$, David Aebischer ${ }^{1}$ and Michael \\ Detmar $^{1}$ \\ ${ }^{1}$ Institute of Pharmaceutical Sciences, Swiss Federal Institute of Technology, ETH Zurich, Zurich, Switzerland \\ Correspondence to: Michael Detmar, email: michael.detmar@pharma.ethz.ch \\ Keywords: inflammation, lymphangiogenesis, VEGF-C, Immunology and Microbiology Section, Immune response, Immunity \\ Received: November 10,2015 Accepted: May 25, $2016 \quad$ Published: June 05, 2016
}

\section{ABSTRACT}

Vascular endothelial growth factor-C (VEGF-C)-induced lymphangiogenesis and increased tissue drainage have been reported to inhibit acute and chronic inflammation, and an activated lymphatic endothelium might mediate peripheral tolerance. Using transgenic mice overexpressing VEGF-C in the skin, we found that under inflammatory conditions, VEGF-C-mediated expansion of the cutaneous lymphatic network establishes an immune-inhibitory microenvironment characterised by increased regulatory $T$ (Treg) cells, immature CD11c+CD11b+ dendritic cells (DCs) and CD8+ cells exhibiting decreased effector function. Strikingly, lymphatic endothelial cell (LEC)-conditioned media (CM) potently suppress DC maturation with reduced expression of MHCII, CD40, and IL-6, and increased IL-10 and CCL2 expression. We identify an imbalance in prostaglandin synthase expression after LEC activation, favoring anti-inflammatory prostacyclin synthesis. Importantly, blockade of LEC prostaglandin synthesis partially restores DC maturity. LECs also produce TGF-ß1, contributing to the immune-inhibitory microenvironment. This study identifies novel mechanisms by which the lymphatic endothelium modulates cellular immune responses to limit inflammation.

\section{INTRODUCTION}

The lymphatic vascular system plays a key role in the transport of interstitial fluid, antigens and immune cells from the periphery to lymph nodes where adaptive immune responses are generated. Expansion of the lymphatic network is observed in numerous inflammatory conditions [1-3], and transgenic overexpression or intradermal injection of the lymphangiogenic factor vascular endothelial growth factor (VEGF)-C inhibits acute and chronic skin inflammation [4-8]. Similarly, viral VEGF-C administration reduced joint lesion severity in chronically inflamed arthritic joints [9] and provided protection against experimental inflammatory bowel disease [10], whereas blockade of VEGFR3 signaling aggravated inflammatory bowel disease [11]. Enhanced lymphatic drainage function has been implicated as the primary mechanism underlying these potent antiinflammatory effects of VEGF-C. However, VEGF-C may also directly attenuate cellular immunity via regulation of macrophage plasticity and activation $[10,12,13]$. Moreover, activated lymphatic endothelial cells (LECs) are involved in the induction of peripheral tolerance [14-18] and might play a role in the generation of an immunotolerant tumor microenvironment [19].

In the present study, we investigated if VEGF-C regulates cellular immunity in cutaneous inflammation, and whether it acts directly on inflammatory cells or indirectly via activation and expansion of the lymphatic endothelium, using K14-VEGF-C transgenic mice that express human VEGF-C in the skin under control of the keratin-14 promoter [20]. These mice have an expansion of lymphatic but not blood vessels in the skin [20] and show reduced inflammation during chemical skin carcinogenesis [21], acute bacterial pathogen-induced skin inflammation [8], in response to UVB irradiation, and in oxazoloneinduced delayed-type hypersensensitivity reactions [5]. We used the PKC activator 12-O-tetradecanoylphorbol-13acetate (TPA) to induce chronic skin inflammation. This was based on its ability to induce epidermal hyperplasia 
$[22,23]$ and enhance the K14-promoter driven transgene expression [21, 24, 25]. We found that VEGF-C-mediated expansion of the lymphatic network establishes an immune-inhibitory cutaneous microenvironment. VEGF-C had no direct effects on dendritic cell (DC) maturation but LEC-conditioned media (CM) potently suppressed DC maturation, which was partially restored upon blockade of LEC prostaglandin synthesis. This study identifies a new mechanism by which the expanded lymphatic vasculature modulates cellular immune responses and limits inflammation.

\section{RESULTS}

\section{Reduced antigen-presentation capacity in the inflamed skin of VEGFC transgenic mice}

Skin lysates from K14-VEGFC mice contained VEGF-C protein (Supplementary Figure 1A) whose levels were strongly increased under inflammatory conditions, confirming efficient transgene expression in the skin. VEGF-C levels were also higher in the sera of uninflamed and inflamed K14-VEGFC mice than in wildtype (WT) littermate controls (Supplementary Figure 1B). The lymphatic network in the normal and inflamed skin of K14-VEGFC mice was significantly expanded, as determined by staining for the lymphatic specific marker LYVE-1 (Supplementary Figure 1C and 1D), which confirmed that the transgenic VEGF-C was biologically active. Although dilated, lymphatic vessels in K14-VEGFC mice contained button-type junctions that were similar to those observed in wildtype mice when co-stained for LYVE-1 and VE-cadherin (Supplementary Figure 1E).

We next investigated the effects of VEGF-C overexpression on the immune cell infiltrates in inflamed skin. No differences in the proportions of CD11b+ cells were detected in the normal skin of K14-VEGFC mice (Figure 1A), whereas these mice had elevated numbers of $\mathrm{CD} 11 \mathrm{~b}+$ cells under inflammatory conditions (Figure 1A). This was predominantly due to a significant increase in the CD11c + CD11b + DC population (Figure 1B). A slight, but not significant increase in $\mathrm{CD} 11 \mathrm{~b}+/ \mathrm{F} 4 / 80+$ macrophages and CD11b+/Gr-1+ myeloid derived suppressor cells was also observed (Supplementary Figure 1F-1G).

We next examined the effects of VEGF-C overexpression on DC subpopulations. No differences in the proportions of $\mathrm{CD} 11 \mathrm{c}+\mathrm{CD} 11 \mathrm{~b}+$ cells expressing high levels of MHCII invariant chain I-A/I-E were observed between uninflamed WT mice and K14-VEGFC mice, as assessed by flow cytometry (Figure 1C). Under inflammatory conditions however, significantly fewer CD11c+CD11b + cells expressed high levels of I-A/I-E in the skin of K14-VEGFC mice (Figure 1C). Similarly, in the absence of inflammation, no significant differences in the levels of co-stimulatory CD80 or CD40 were observed in $\mathrm{CD} 11 \mathrm{c}+\mathrm{CD} 11 \mathrm{~b}+\mathrm{I}-\mathrm{A} / \mathrm{I}-\mathrm{E}^{\mathrm{hi}}$ cells (Figure 1D-1E), whereas under inflammatory conditions, the $\mathrm{CD} 11 \mathrm{c}+\mathrm{CD} 11 \mathrm{~b}+\mathrm{I}-\mathrm{A} / \mathrm{I}-\mathrm{E}^{\mathrm{hi}}$ cells in the skin of K14-VEGFC mice had significantly reduced levels of co-stimulatory CD80 (Figure 1D). CD40 expression was also slightly reduced, however this was not statistically significant (Figure 1E). Importantly, CD11c+CD11b+ cells in the skin of inflamed K14-VEGFC mice expressed significantly lower levels of CCR7 (Figure 1F), a key chemokine receptor implicated in DC migration to draining lymph nodes [26].

\section{Inflamed skin of K14-VEGFC mice has elevated regulatory $T$ cell numbers}

Immature dendritic cells have the ability to prime naive $\mathrm{T}$ cells to differentiate into Treg cells [27, 28]. Using immunofluorescence stains and image quantification, we found significantly increased numbers of both CD4+ and CD8+ cells in inflamed skin when compared to normal skin (Supplementary Figure 1H-1I), but no significant differences were observed in WT versus K14-VEGFC mice. The numbers of immunosuppressive Tregs, quantified via CD4+Foxp3+ co-staining (Figure 1G), were significantly higher in K14-VEGFC mice than in WT mice (Figure $1 \mathrm{H}$ ) in inflamed skin. No significant differences in the proportions of $\mathrm{CD} 4+, \mathrm{CD} 8+$ or CD4+Foxp3+ cells were observed in the thymus $(\mathrm{CD} 4+, \mathrm{CD} 8+, \mathrm{CD} 4+\mathrm{CD} 8+$ or CD4+Foxp3), spleen, LNs and blood (CD4+, CD8+, or CD4+Foxp3), when comparing K14-VEGFC mice with WT controls (Supplementary Figure 2A-2E), indicating that the differences in the proportions of Foxp3+ cells in the skin are due to a local effect and not a result of systemic differences between transgenic and WT mice.

TGF- $\beta 1$ is a potent immunomodulatory cytokine implicated in the generation of tolerogenic dendritic cells $[29,30]$ and is a critical factor in both the generation and maintenance of Tregs [31, 32], and their effector function $[33,34]$. In untreated skin, no significant differences in TGF-ß1 protein levels, determined by ELISA, were detected (Figure 1I), whereas after a single treatment with TPA, TGF-ß1 was significantly upregulated in the skin of K14-VEGFC mice (Figure 1I). Cultured LECs produced relatively high levels of TGF- 31 , as determined by ELISA of cell culture supernatants $(345.0 \pm 132.0 \mathrm{pg} / \mathrm{mL})$ (Figure $1 \mathrm{~J})$. TGF- 31 was not significantly regulated by VEGF-C directly; however, it was significantly increased nearly 3 fold upon stimulation with TPA $(909.3 \pm 167.2 \mathrm{pg} / \mathrm{mL})$ (Figure 1J), suggesting that the expanded and activated lymphatic endothelium in VEGFC transgenic mice contributed to the tolerogenic milieu via production of TGF-ß1. 

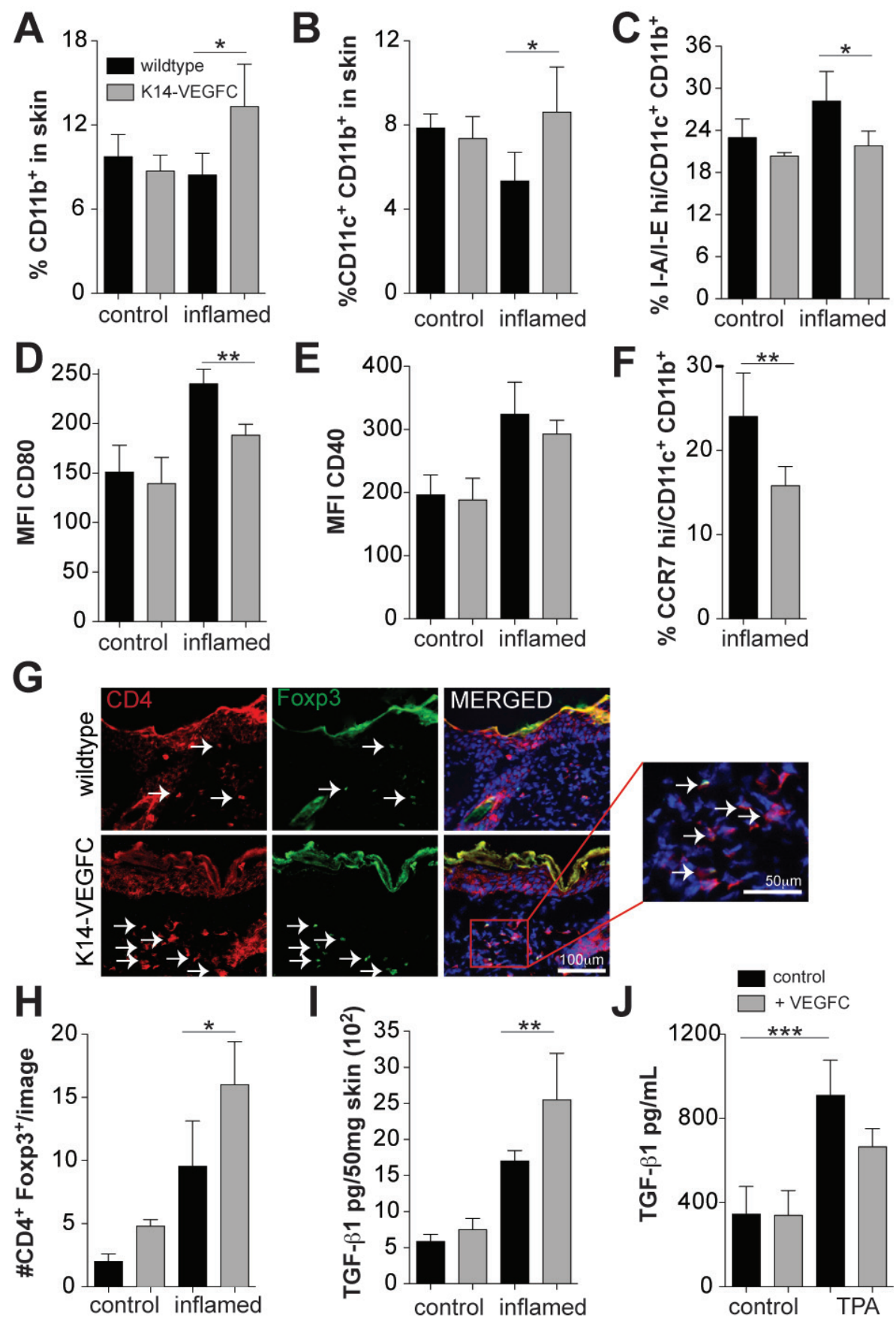

Figure 1: Inflamed skin of K14-VEGFC mice has elevated numbers of immature CD11c+CD11b+ cells and increased proportions of regulatory $\mathbf{T}$ cells. Flow cytometry was used to determine the proportions of CD11b+(A) and CD11c $+\mathrm{CD} 11 \mathrm{~b}+(\mathbf{B})$ cells in the skin of control $(n=3$ per genotype) and inflamed ( $n=4$ per genotype) wildtype and K14-VEGFC mice. CD11c+CD11b+cells were also assessed for their expression of I-A/I-E (MHCII) (C), CD80 (D), CD40 (E) and CCR7 (F) $(n=4$ per genotype/treatment except $n=7$ for CCR7 in inflamed K14-VEGFC). Skin sections from wildtype and K14-VEFC control ( $n=3$ per genotype) and inflamed ( $n=$ 4 per genotype) mice were co-stained for CD4 and Foxp3. Representative fluorescent images for inflamed skin are shown in (G) (Scale bar: $100 \mu \mathrm{m}$ ). Left panels: CD4 (red); middle panels: Foxp3 (green); right panels: merged image of CD4, Foxp3, and Hoechst (blue) to visualize nuclei. The insert is a magnified region of the merged image as indicated (scale bar: $50 \mu \mathrm{m}$ ). Arrows indicate Foxp3+CD4+ cells. Foxp $3+\mathrm{CD} 4+$ cells per image were quantified and are shown in $(\mathbf{H})$ (control $n=3$, inflamed $n=4)$. Black bars: wildtype mice. Grey bars: K14-VEGFC mice. TGF- $\beta 1$ protein levels were quantified in the back skin of control and inflamed wildtype (black bars) and K14-VEGFC mice (grey bars) ( $n=4$ per treatment and genotype) by ELISA (I) TGF- $\beta 1$ protein levels were also quantified in cell culture supernatants taken from TPA $(20 \mathrm{ng} / \mathrm{mL})$ and recombinant VEGF-C $(500 \mathrm{ng} / \mathrm{mL})$ treated lymphatic endothelial cells $(\mathbf{J})$ For all graphs, data shown are the mean $\pm \mathrm{SD}$. Two-way ANOVA with Bonferroni post-test was used to assess statistical significance except (F) where Student's t-test was applied. ${ }^{*} p<0.05,{ }^{* *} p<0.01$. 
Skin-draining lymph nodes of inflamed K14VEGFC mice are reduced in size, cellularity and effector cell activity

The inguinal LNs of inflamed K14-VEGFC mice were significantly smaller than those of inflamed WT mice (Figure 2A and 2B). The leukocyte cellularity was also significantly reduced (Figure 2C), indicating that the inflammatory response was attenuated. Using flow cytometry, a significant reduction in the number of $\mathrm{CD} 11 \mathrm{c}+\mathrm{CD} 11 \mathrm{~b}+$ cells was observed in the skin draining LNs of inflamed, but not uninflamed, K14-VEGFC mice (Figure 2D). Reflecting the findings in the skin, $\mathrm{CD} 11 \mathrm{c}+\mathrm{CD} 11 \mathrm{~b}+$ cells in draining LNs of inflamed K14VEGFC mice expressed significantly lower levels of I-A/ I-E, costimulatory CD40 and CCR7 (Figure 2E, 2F and $2 \mathrm{G})$.

We next investigated the ability of CD11c $+\mathrm{CD} 11 \mathrm{~b}+$ cells to migrate from inflamed skin to the skin-draining LNs (schematic shown in Figure 2H). Following dermal FITC painting, the skin draining LNs of K14-VEGFC mice contained significantly fewer FITC $+\mathrm{CD} 11 \mathrm{c}+\mathrm{CD} 11 \mathrm{~b}+$ cells that had migrated from the inflamed dermis (Figure $2 \mathrm{I}$ and $2 \mathrm{~J}$ ). This reduced migration most likely resulted from the observed decreased expression of CCR7 on $\mathrm{CD} 11 \mathrm{c}+\mathrm{CD} 11 \mathrm{~b}+$ cells. Alternatively, a deregulated CCL21 gradient may also disrupt effective DC trafficking to draining LNs. We found that uninflamed and TPAtreated (single application) skin of K14-VEGFC mice had significantly higher levels of CCL21 than WT controls, and TPA-treatment significantly increased CCL21 expression (Supplementary Figure 3A), indicating that the normal tissue distribution of CCL21 might be altered in K14-VEGFC mice. We also observed increased dermal tissue clearance of a lymphatic specific tracer, with a reduced tissue half-life time in K14-VEGFC mice when compared to wildtype mice (Supplementary Figure 3B). This indicates that VEGF-C and the resulting expanded lymphatic vasculature led to increased lymph flow, which suggests that the observed reduced migration of DCs to draining LNs is not due to decreased lymphatic function in these mice. Increased flow from inflamed skin could however impact upon the dermal inflammatory milieu, for example by increasing the drainage of inflammatory molecules.

\section{The inflammatory response in skin draining LNs is reduced in K14-VEGFC mice}

We next investigated other inflammatory cell populations within inflammation-draining LNs. Although no differences in the proportions of $\mathrm{B} 220+, \mathrm{TCR} \beta+, \mathrm{CD} 4+$ and CD8+ cells were observed when comparing WT with K14-VEGFC inflamed LNs (Figure 2K), inflammationdraining LNs of K14-VEGFC mice had significantly fewer $\mathrm{B} 220+, \mathrm{TCR} \beta+, \mathrm{CD} 4+$ and $\mathrm{CD} 8+$ cells, indicative of a reduced inflammatory response (Figure $2 \mathrm{~L}$ ). Since migratory activated DCs from sites of inflammation present antigens to $\mathrm{T}$ cells within draining LNs, the activity of $\mathrm{T}$ cells within the draining node should reflect the frequency and activation status of intra-nodal DCs. We therefore isolated CD8+ cells from untreated and inflamed mice and examined IFN- $\gamma$ production following in vitro stimulation with PMA/ionomycin. In agreement with our observation that draining LNs of K14-VEGFC mice had reduced numbers of DCs exhibiting a more immature phenotype, inguinal LNs of K14-VEGFC mice contained significantly fewer IFN- $\gamma$-producing CD8+ cells. These differences were not observed in untreated mice or nonskin-draining (mesenteric) LNs (Figure 2M-2N).

\section{VEGF-C does not directly modulate the phenotype of dendritic cells}

We next tested whether DCs express VEGFR3, the receptor for VEGF-C. CD11c+BMDCs significantly upregulated VEGFR3, and to a lesser extent VEGFR2 and VEGFR1, in response to IFN- $\gamma$ or TPA stimulation (Figure $3 \mathrm{~A})$. However, VEGFC was not chemotactic for control or IFN- $\gamma$-stimulated BMDCs, whereas CCL21 promoted chemotactic migration (Figure 3B). Expression of CD40 (Figure 3C), CD80 (Figure 3D), and CD86 (Figure 3E) was not significantly altered on control, IFN- $\gamma$ - or TPAstimulated BMDCs upon addition of VEGF-C (500 ng/ $\mathrm{mL}$ ). Similarly, recombinant VEGF-C had no effect on the expression of the MHCII invariant chain I-A/I-E (Figure 3F). The ability of VEGF-C to modulate the expression of pro- and anti-inflammatory cytokines (IL-6, IL-10, TNF $\alpha$ ) (Figure 3G, 3H and 3I), the chemokine CCL2 (Figure $3 \mathrm{~J})$ and the expression of the chemokine receptor CCR7 (Figure 3K) was also analysed using realtime PCR. In unstimulated and IFN- $\gamma$ - or TPA-stimulated cells, VEGFC had very minor to no effects on the expression of these genes.

\section{Lymphatic endothelial cell conditioned media induce immunosuppressive dendritic cells}

As VEGF-C had no direct effect on DC maturation, we investigated if LECs might produce factors that modulate the phenotype of DCs. BMDCs were treated with conditioned media collected from LECs (LEC-CM) and cultured with or without IFN- $\gamma$. Using flow cytometry, these cells were assessed for expression of CD80, CD40, CD86, I-A/I-E and CCR7 (Figure 4A-4E). Treatment of BMDCs with LEC-CM significantly downregulated expression of co-stimulatory CD40 and CD86, reduced the expression of I-A/I-E and also significantly reduced CCR7 expression. We then analyzed the inflammatory cytokine profiles of these DCs using quantitative RT- 

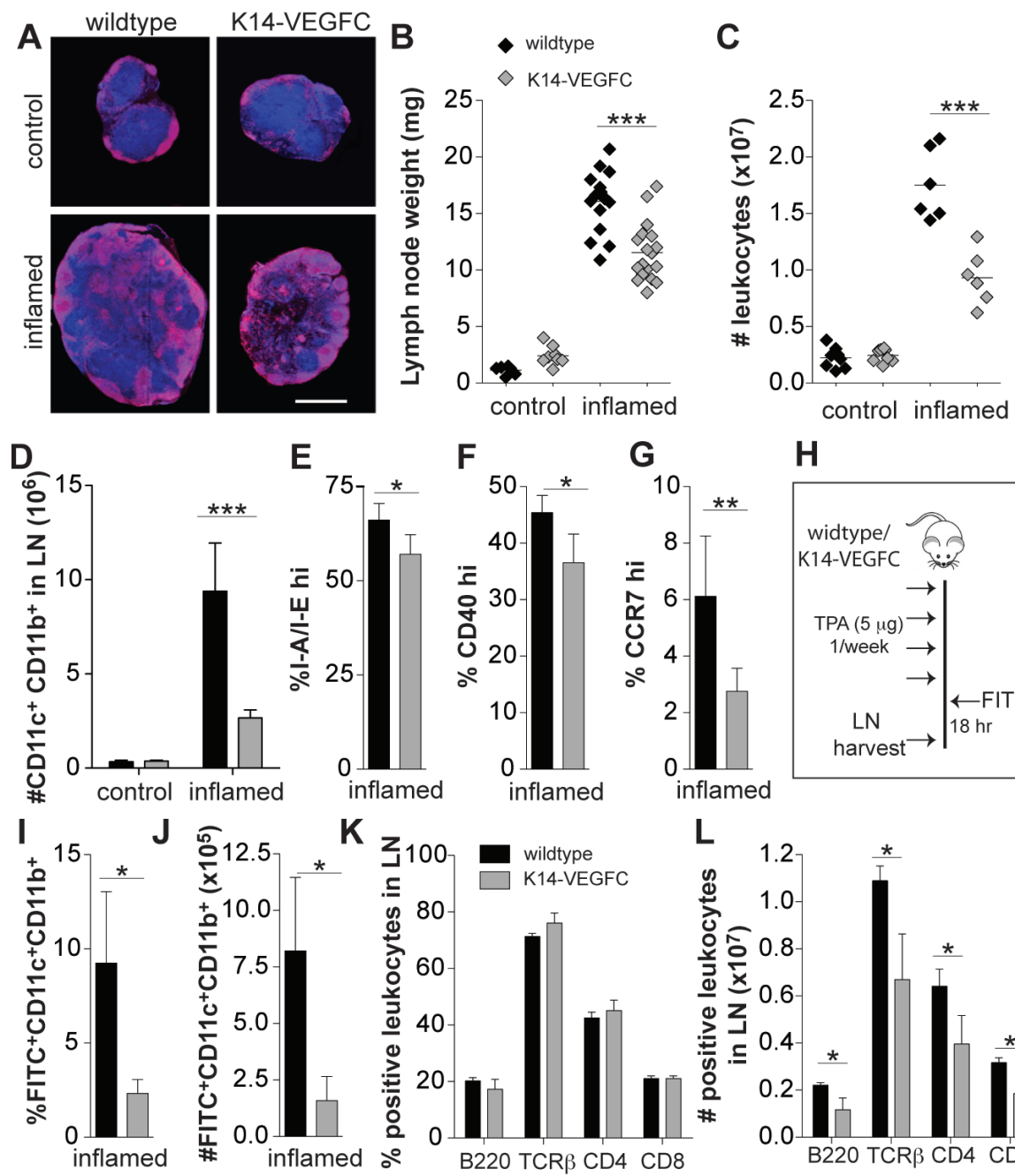

$\mathrm{E}_{75, *}$

$\mathrm{F}$

$\mathbf{F} \mathbf{G}$

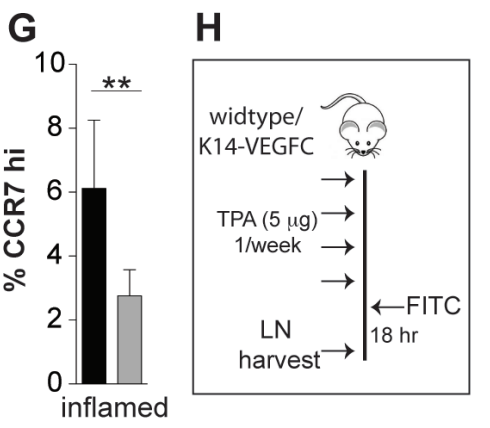

M

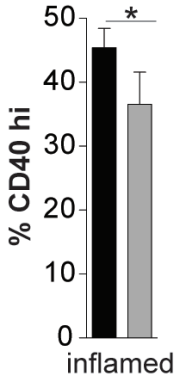

L
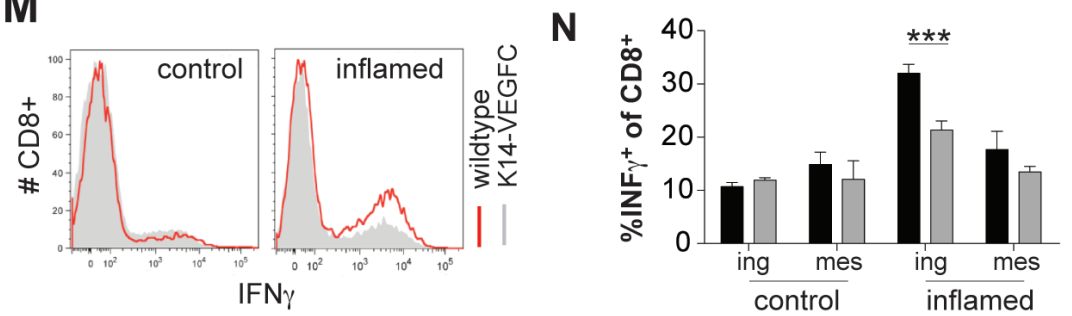

Figure 2: A reduced inflammatory response is observed in skin-draining inguinal LNs of K14-VEGFC mice. Skindraining inguinal LNs of untreated and inflamed wildtype and K14-VEGFC mice were harvested. Central transverse sections of inguinal LNs were stained for B220 (red) and Hoechst (blue). Representative immunofluorescent images are shown in (A) (Scale bar: $1 \mathrm{~mm}$ ). LNs were weighed $(\mathbf{B})$ and the cellularity determined using a hemocytometer $(\mathbf{C})$ Each data point represents a single lymph node. The horizontal line represents the mean. Inguinal LNs from untreated ( $n=3$ per genotype) and inflamed ( $n=4$ per genotype) mice were analysed for their numbers of $\mathrm{CD} 11 \mathrm{c}^{+} \mathrm{CD} 11 \mathrm{~b}^{+}$cells using flow cytometry $(\mathbf{D})$ Proportions of I-A/I-E $(\mathbf{E})$, co-stimulatory CD $40^{\text {hi }}(\mathbf{F})$ and CCR $7^{\text {hi }}(\mathbf{G})$ cells were also quantified on $\mathrm{CD} 11 \mathrm{c}^{+} \mathrm{CD} 11 \mathrm{~b}^{+}$cells within inflamed inguinal $\mathrm{LNs}(n=4,4$, and 7 , respectively). Data are presented as mean \pm $\mathrm{SD}$. To investigate the ability of $\mathrm{CD} 11 \mathrm{c}^{+} \mathrm{CD} 11 \mathrm{~b}^{+}$cells to migrate from inflamed skin to skin-draining $\mathrm{LNs}, 5 \%$ FITC thioglycolate/acetone $1: 1 \mathrm{v} / \mathrm{v}$ was applied to the inflamed backskin of wildtype $(n=4)$ and K14-VEGFC mice $(n=4)$ see schematic $(\mathbf{H})$ The proportions of FITC-positive CD11c+CD11b+ cells in the draining LNs (axillary + inguinal) were quantified by flow cytometry (I) and the total number of migrating cells calculated (J) Proportions of B220, TCR $\beta$, CD4 and CD8 positive cells were quantified using flow cytometry in skindraining inguinal LNs from inflamed wildtype $(n=3)$ and K14-VEGFC $(n=3)$ mice $(\mathbf{K})$ Total cellularity in the lymph node for each marker was also quantified and is shown in (L) Leukocytes isolated from inguinal and mesenteric LNs were stimulated with PMA/ionomycin and analysed for IFN- $\gamma$-production. Representative flow cytometry histograms are shown (M) Proportions of IFN- $\gamma^{+} \mathrm{CD}^{+} \mathrm{T}$ cells in leukocytes isolated from control and inflamed mice are shown $(\mathbf{N})(n=4$ per treatment and genotype). All data are presented as mean \pm SD. Figures B-D were analysed using Two-way ANOVA with Bonferroni's post-test to assess statistical significance. Student's t-test was applied to all other figures. ${ }^{*} p<0.05,{ }^{* *} p<0.01 * * * p<0.001$. 
PCR and found that treatment with LEC-CM also significantly reduced the expression of pro-inflammatory IL-6 (Figure 4F) when stimulated with IFN- $\gamma$. TNF- $\alpha$ was also reduced under control and IFN- $\gamma$ stimulation, however, this was not statistically significant (Figure 4G). Furthermore, LEC-CM significantly upregulated the anti-inflammatory cytokine IL-10 (Figure 4H) and the chemokine CCL2 (Figure 4I). Collectively, these data reveal that LECs produce a factor, or factors, that potently induce an immature, less inflammatory phenotype in DCs, characterized by a potentially reduced capacity for antigen presentation and an anti-inflammatory cytokine production profile. Given the observed elevated TGF- $\beta$ levels in inflamed skin of VEGF-C mice (Figure 1I) and the ability of LECs to produce TGF- 3 (Figure 1J), we investigated if TGF- $\beta$ could induce the production of DCs with a less mature phenotype. Addition of TGF- $\beta$ during DC maturation assays had no effect on the expression of
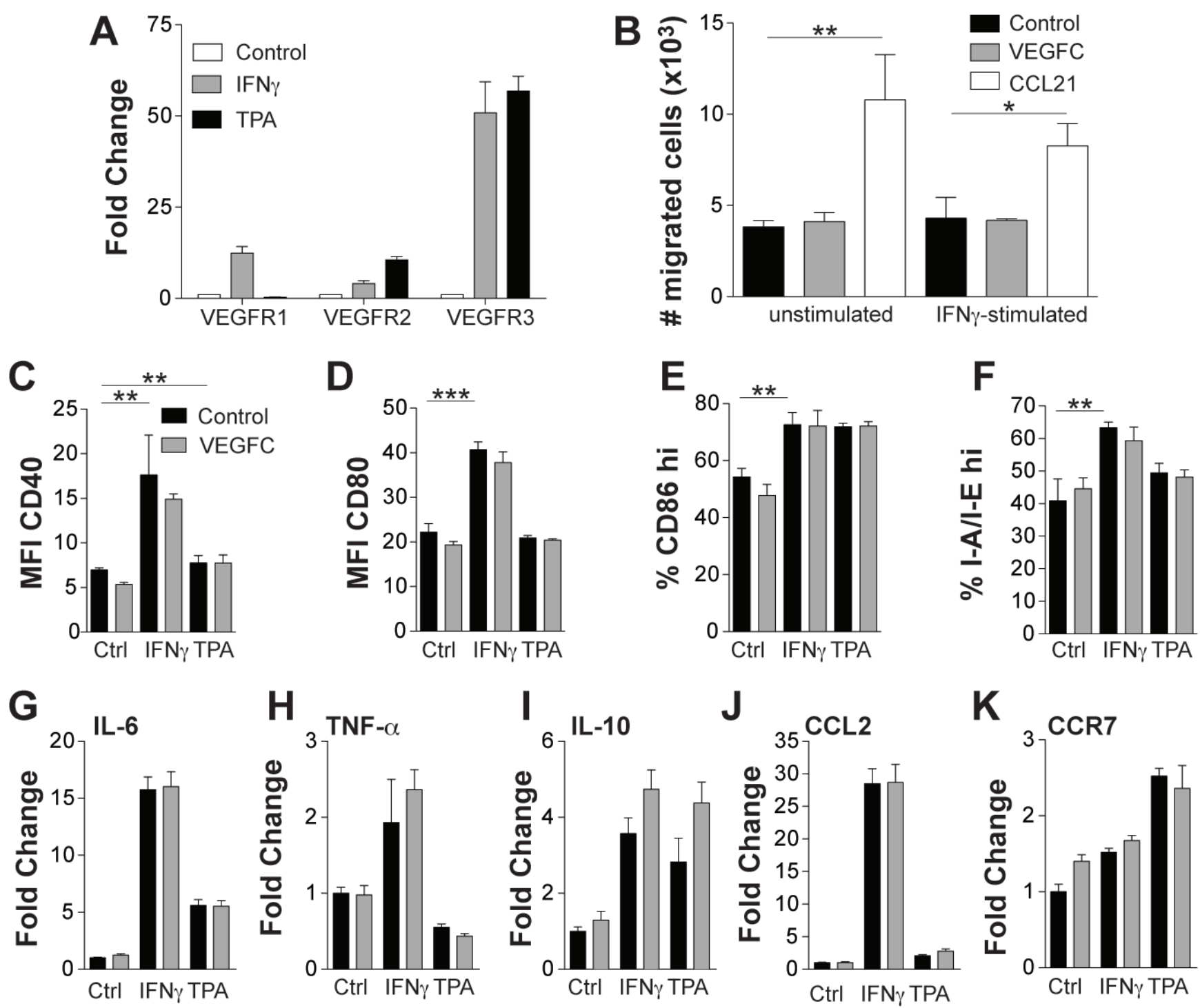

Figure 3: VEGF-C does not directly modulate the phenotype of CD11c+ cells. Bone marrow derived CD11c + cells were stimulated in vitro for 24 hours with IFN- $\gamma(100 \mathrm{ng} / \mathrm{mL})$ or TPA $(10 \mathrm{ng} / \mathrm{mL})$ and assessed for VEGFR expression using quantitative RTPCR (A) Data are shown as fold change relative to control treated cells. Control and IFN- $\gamma$-stimulated bone marrow derived CD11c+ cells were assessed for their ability to migrate towards VEGF-C $(500 \mathrm{ng} / \mathrm{mL})$ in an in vitro transwell migration assay (B) The positive control of dendritic cell migration towards CCL21 $(100 \mathrm{ng} / \mathrm{mL})$ is also shown. Mean number of cells migrated per well $(n=3)$ is shown \pm SD. Bone marrow derived CD11 c + cells were stimulated for 24 hours in vitro with IFN- $\gamma(100 \mathrm{ng} / \mathrm{mL})$ or TPA $(10 \mathrm{ng} / \mathrm{mL})$ in the presence or absence of VEGF-C (500 ng/mL) and were assessed for their expression of CD40 (C), CD80 (D), CD86 (E) and I-A/I-E (F) using flow cytometry. Data are shown as mean $\pm \mathrm{SD}$. No statistically significant differences were observed when comparing control to VEGF-C treated cells with or without IFN- $\gamma$ or TPA stimulation. mRNA isolated from likewise treated cells were assessed using quantitative real-time PCR for the expression of IL-6 (G), TNF- $\alpha(\mathbf{H})$, IL-10 (I), CCL2 (J) and CCR7 (K). Data are shown as the fold change relative to control treated cells. Student's t-test was used to assess statistical significance (Figures B-F). ${ }^{*} p<0.05,{ }^{* *} p<0.01 * * * p<0.001$. 
I-A/I-E or CD40 (Supplementary Figure 4). Furthermore, addition of TGF- $\beta$ signaling inhibitors (LY-364947 and SB-431542) failed to block the potent maturation inhibitory effect of LEC-CM, indicating that TGF- $\beta$ does not play a major role in the LEC-induced inhibition of DC maturation (Supplementary Figure 4).

\section{Blockade of prostaglandin synthesis partially reverts $\mathrm{LEC}-\mathrm{CM}$ effects on dendritic cell function}

Prostaglandins are potent modulators of inflammation. We next investigated if prostaglandins might contribute to the immunosuppressive effects of LEC-CM on DCs. BMDCs were cultured with CM generated from LECs treated or not with the COX-2 inhibitor Celecoxib and were analysed using RT-PCR and flow cytometry for expression of key cytokines, chemokines and surface markers. Blockade of COX2 reduced LEC-CM-mediated upregulation of IL-10 expression in BMDCs by approximately 40\% (Figure 5A) and also reduced LEC-CM-induced upregulation of CCL2 expression by approximately 50\% (Figure 5B). Celecoxib treatment of LECs also partially reversed LECCM-mediated downregulation of CD40 expression on the surface of BMDCs (Figure 5C), potentially restoring effective antigen presentation function of these cells.

The generation of specific prostaglandins is dependent upon the availability of their respective synthases. We analyzed in cultured LECs the expression of two downstream prostaglandin synthases, prostacyclin (prostaglandin I2, $\mathrm{PGI}_{2}$ ) synthase (PTGIS) and prostaglandin E synthase (PGES). LECs increased the expression of PTGIS approximately 3-fold (Figure 5D) upon treatment with TPA, and reduced the expression of PGES to approximately $40 \%$ of that expressed by control cells (Figure 5E). In line with this, cultured LECs were found to produce prostacyclin (assessed by ELISA of cell culture supernatants), and upregulated its production upon stimulation with TPA (Figure 5F). Importantly, blockade
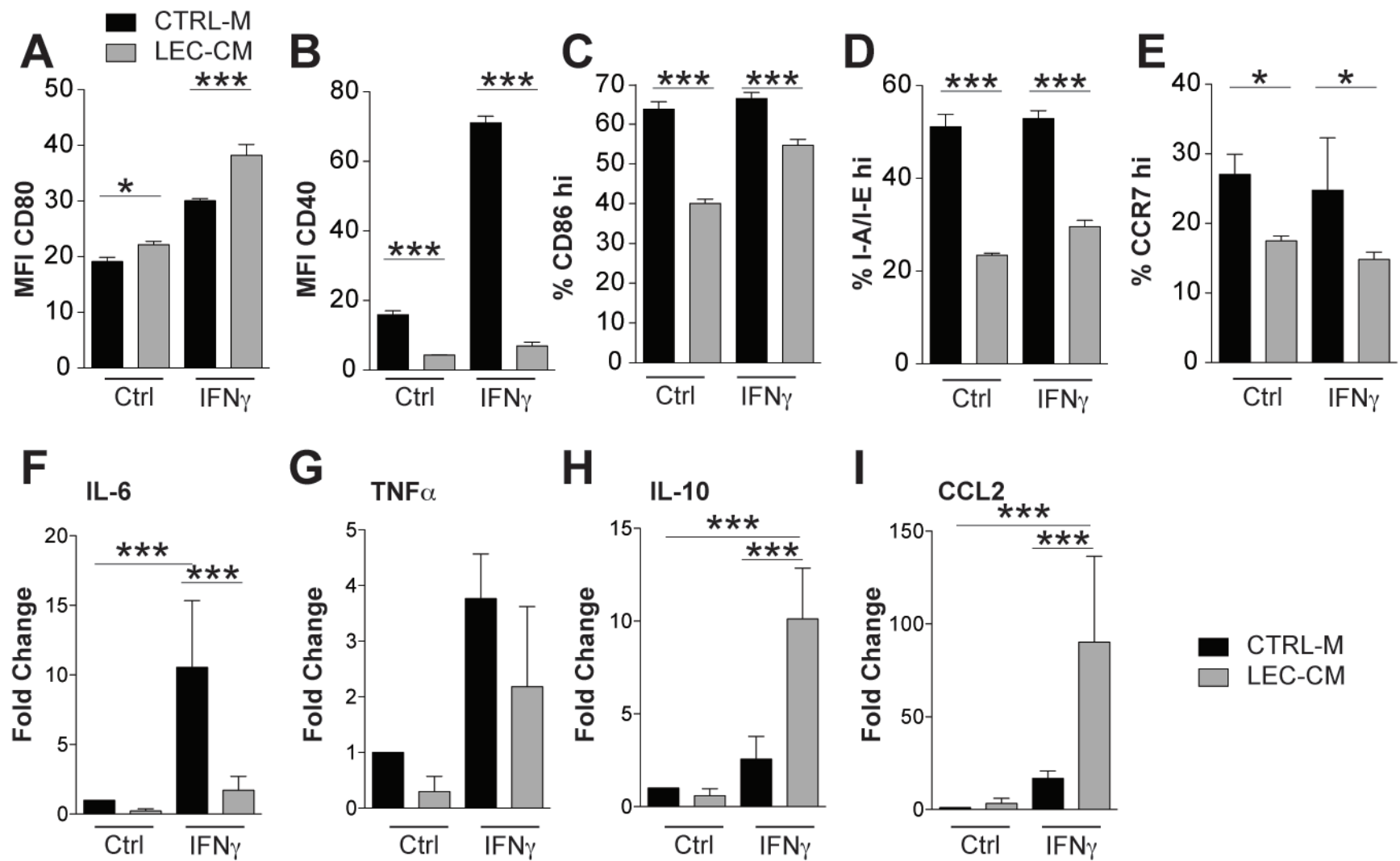

Figure 4: Lymphatic endothelial cell conditioned media induce an immunosuppressive phenotype in bone marrow derived CD11c+ cells. Bone marrow derived CD11c+ cells were treated with control media (CTRL-M) or lymphatic endothelial cellconditioned media (LEC-CM) for 24 hours with or without IFN- $\gamma$ stimulation $(100 \mathrm{ng} / \mathrm{mL})$. Flow cytometric analysis of their expression of CD80 (A), CD40 (B), I-A/I-E (C), CD86 (D) and CCR7 (E) was performed with either the median fluorescence intensity (MFI) or percentage of cells expressing high marker levels shown. Data shown are representative of three independent biological replicates. mRNA isolated from likewise treated cells was analysed using RT-PCR for the expression of IL-6 (F), TNF $\alpha(\mathbf{G})$, IL-10 (H) and CCL2 (I) Data are shown as the mean fold change relative to control treated cells (normalized to 1) of three independent biological replicates. Statistical significance was assessed using the Two-way (A-E) and One-Way (F-I) ANOVA with Bonferroni post-tests.. ${ }^{*} p<0.05, * * p<0.01, * * * p$ $<0.001$. 

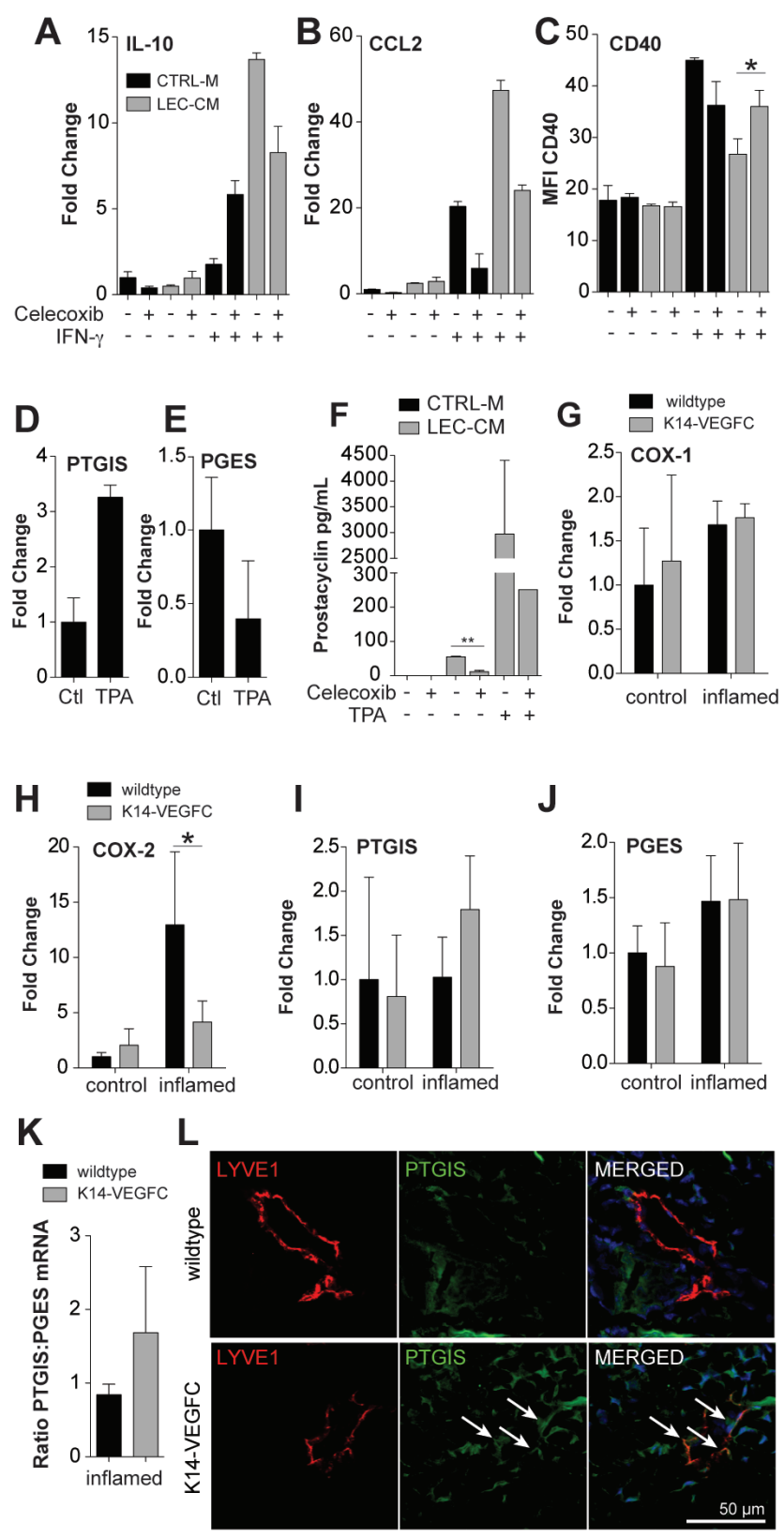

Figure 5: Blockade of prostaglandin synthesis partially reverts immunosupressive effects of LEC conditioned media. Bone marrow derived CD11c+ cells were treated for 24 hours with either control media (CTRL-M) or lymphatic endothelial cell-conditioned media (LEC-CM) that was generated \pm Celecoxib $(20 \mu \mathrm{M})$. BMDCs were stimulated with \pm IFN- $\gamma(100 \mathrm{ng} / \mathrm{mL})$ as shown. mRNAs from treated cells were then analysed using RT-PCR for the expression of IL-10 (A) and CCL2 (B) Data are shown as the fold change relative to control treated cells and are representative of three independent biological replicates. Likewise treated cells were also analysed using flow cytometry for their expression of CD40 (C) Data are shown as the median fluorescence intensity and are representative of two biological replicates. LECs were stimulated with TPA $(10 \mathrm{ng} / \mathrm{mL})$ for 6 hours and the relative expression of prostacyclin synthase (PTGIS) (D) and prostaglandin E synthase (PGES) (E) compared to Rplp0 was assessed using real-time PCR. Data are shown as the fold change relative to control treated cells (normalized to 1) and are representative of three independent biological replicates. Prostacyclin levels in cell culture supernatants were assessed via ELISA. LECs were cultured for 48 hours with or without celecoxib $(20 \mu \mathrm{M})$ and TPA $(10 \mathrm{ng} / \mathrm{mL})($ F) RTPCR of mRNA extracted from the skin of wildtype and K14-VEGFC, control $(n=3)$ and inflamed $(n=3-4)$ mice was used to assess the relative expression of COX-1 (G), COX-2 (H), PTGIS (I) and PGES (J) when compared to Rplpo. Data are shown as the fold change \pm SD relative to control-treated wildtype mice (normalized to 1). The ratio of the relative expression of PTGIS:PGES is shown in (K) Representative confocal images of inflamed back skin of wildtype and K14-VEGFC mice, stained for LYVE-1 (red) and PTGIS (green), scale bar $50 \mu \mathrm{m}$ (L) We consistently observed more PTGIS staining in K14-VEGFC skin, both in lymphatic endothelial cells (arrows) and non-endothelial cells. Note that lymphatic vessels of similar size were chosen for better comparability of the staining pattern. Student's t-test was used to assess statistical significance in A-C, F and K. Two-way ANOVA with Bonferroni's post-test was used in G-J. ${ }^{*} p<0.05$. 
of prostaglandin synthesis using Celecoxib significantly reduced prostacyclin levels in LEC-CM (Figure 5F).

We next investigated the levels of prostaglandin synthases in the skin of mice. The relative expression levels of COX-1 were largely unchanged following inflammation (Figure 5G), whereas COX-2 was strongly upregulated in the inflamed skin of WT mice (Figure $5 \mathrm{H})$. Strikingly, a similar upregulation of COX-2 was not observed in the inflamed skin of K14-VEGFC mice with expression levels similar to those observed in uninflamed skin (Figure 5H). PTGIS expression was not increased in inflamed WT mice but was upregulated in the inflamed skin of K14-VEGFC mice (Figure 5I). PGES expression was comparably expressed in WT and K14-VEGFC mice (Figure 5J). In inflamed skin, K14-VEGFC had an approximately two fold higher ratio of PTGIS to PGES than WT mice (Figure 5K). In accordance with these findings, the inflamed skin of K14-VEGFC mice showed lymphatic PTGIS staining that was largely absent from the skin of inflamed wildtype controls (Figure 5L). Thus, an increase in the levels of anti-inflammatory (PTGIS) versus pro-inflammatory (PGES) prostaglandin synthases may contribute to the immune-inhibitory microenvironment in the lymphatic rich skin of VEGF-C transgenic mice.

\section{DISCUSSION}

Topical TPA application to the skin induces cutaneous inflammation characterized by increased vascular permeability, swelling and edema, inducing a significant inflammatory cell infiltration within the dermis [35-37]. We have previously reported that transgenic expression of VEGF-C in the skin, resulting

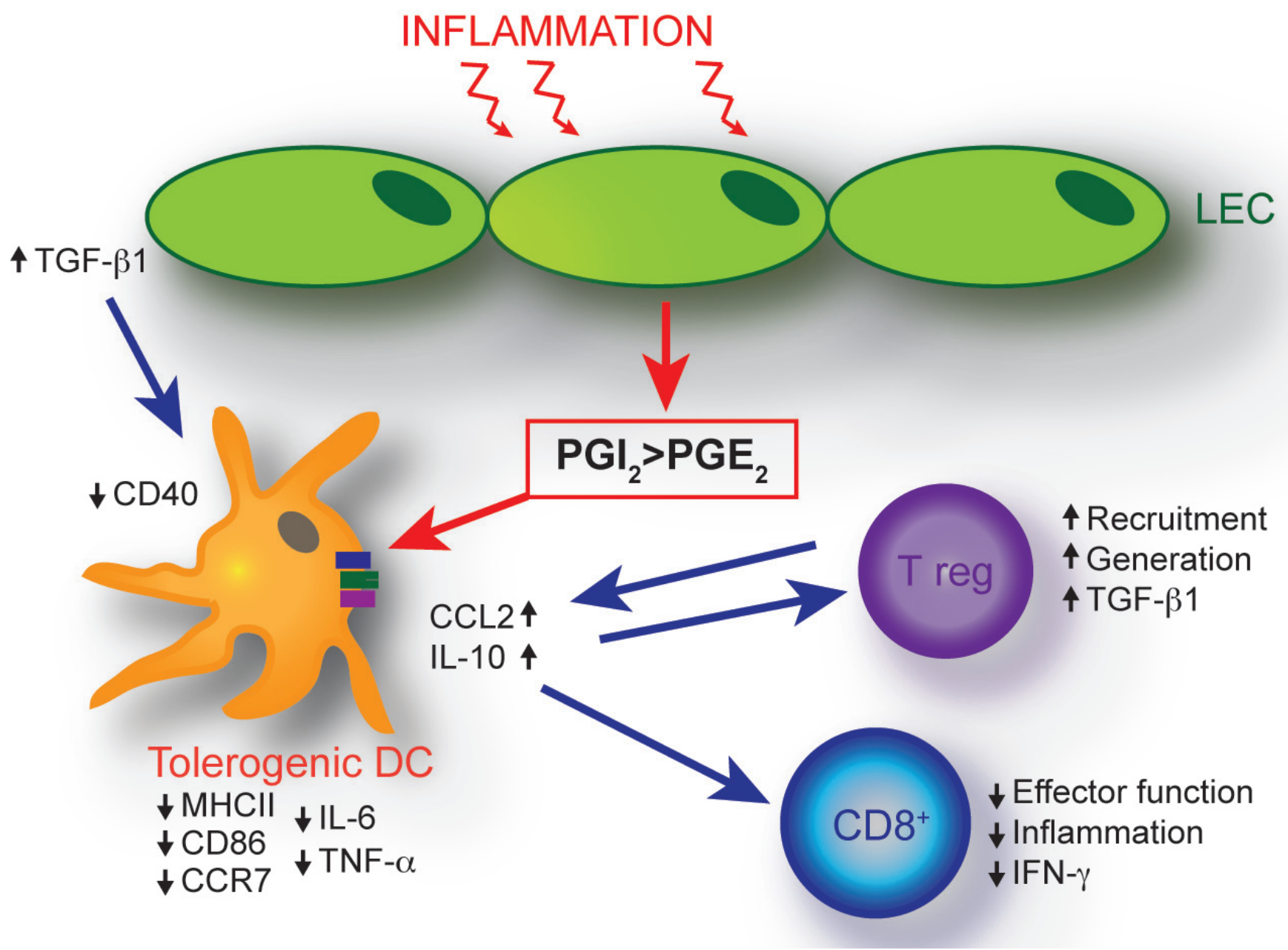

Figure 6: Schematic of proposed mechanisms of LEC-mediated dendritic cell modulation. The VEGF-C-mediated expansion of the inflammatory lymphatic vessel network results in an immune-inhibitory dermal microenvironment. An imbalance in LEC synthesis of prostaglandins, namely a shift towards increased synthesis of the inflammation limiting prostacyclin, concomitant with decreased synthesis of the pro-inflammatory $\mathrm{PGE}_{2}$, represents a key mechanism resulting in the generation of immature DCs with an anti-inflammatory cytokine profile. These effects are compounded by increased LEC-derived TGF- $\beta 1$ production. In addition, the dermal cellular milieu exhibits elevated numbers of Tregs. Decreased DC maturation is implicated in the generation of CD8+ T cells with a reduced ability to produce pro-inflammatory IFN- $\gamma$. 
in an expanded dermal lymphatic network, limits acute skin inflammation and reduces dermal edema formation in response to challenge by oxazolone and UV-B [5]. Interestingly, the application of oxazolone to K14VEGFC mice revealed a significant increase in $\mathrm{CD} 11 \mathrm{~b}+$ cells when compared to WT controls [5]. In the current study, we have more comprehensively characterized the inflammatory infiltrate in response to TPA, and identified a new mechanism how LECs contribute to the attenuation of inflammation.

DCs, the major antigen presenting leukocytes, play crucial roles in inflammation and immunity. Importantly, we found that inflamed skin of K14-VEGFC mice contains significantly higher proportions of CD11c+CD11b+ cells than WT mice. Although increased in number, these cells were less mature, with significantly reduced levels of MHCII, co-stimulatory molecules, and CCR7, suggesting a naïve, tolerogenic phenotype. A defect in DC migration to the draining LNs could result in their accumulation in the skin. Indeed, we found that the ability of DCs to traffic to draining LNs was severely compromised in inflamed skin of K14-VEGFC mice, most likely due to their reduced expression of the key migratory chemokine receptor CCR7 [26, 38].

Clearly, impairment of DC trafficking can severely impact upon the successful generation of active immune responses. As a result, the inflamed skin-draining LNs of K14-VEGFC mice were significantly reduced in their weight, size and cellularity when compared with inflamed WT LNs. Lymph node resident CD11c+CD11b+ cells exhibited reduced antigen presentation capabilities with I-A/I-E and CD40 expressed at lower levels when compared to those in inflamed WT LNs. Importantly, the ability of CD8+ cells in inflamed K14-VEGFC LNs to produce IFN- $\gamma$ upon in vitro stimulation was significantly reduced when compared to those isolated from inflamed WT mice, indicating that skin-derived DCs were not able to activate T-cells efficiently.

Concomitant with a less activated DC phenotype, we also observed an increase in CD4+Foxp3+ Tregs in the inflamed skin of K14-VEGFC mice when compared to WT controls. This is in line with the reported increase of infiltrating Tregs in VEGF-C overexpressing tumour models [19]. Tregs play a critical role in the resolution of inflammation, suppressing both DC and effector T-cell functions (reviewed by [39]). A key immune-regulatory cytokine is TGF- $ß 1$, which is produced by multiple cell types including Tregs and DCs, and at the same time regulates the activity of both these cell types (reviewed in [40]). For example, TGF- $\beta 1$ skews DCs towards a tolerogenic phenotype $[29,41]$, while also modulating the generation and regulatory effects of Tregs [31, 42, 43]. Thus, the observed increased levels of TGF- 31 likely contribute to the immune-inhibitory microenvironment in the inflamed skin of K14-VEGFC mice. Importantly, our data further indicate that LECs are a prominent source of TGF- 31 . Given the largely expanded lymphatic network that we observed in K14-VEGFC mice under inflammatory conditions, it is conceivable that lymphaticderived TGF- $\beta 1$ contributes to immune inhibition in the dermis. However, our data suggest that TGF- $ß 1$ is not the main factor responsible for the immature DC phenotype observed in the skin of K14-VEGF-C mice.

Inhibition of DC maturation has been reported for the closely related vascular endothelial growth factor-A (VEGF-A) in vitro and in vivo [44, 45]. Given that in the presence of elevated VEGF-C DCs were less activated, we first hypothesized that, similar to VEGF-A, VEGF-C might also exert tolerogenic effects on DCs. However, although we found upregulation of VEGFR-3 in DCs, we could not find any direct effect of VEGF-C on those cells in vitro.

Alternatively, the expanded lymphatic endothelium may modulate the maturation of DCs in K14-VEGFC mice. Previously, inflamed LECs were found to downregulate DC expression of costimulatory CD86 via an ICAM-1/Mac-1 dependent adhesive interaction that in turn suppressed the ability of DCs to activate T-cells [46]. Our data suggests that, in addition to TGF- $\beta 1$, LECs may produce other factors that modulate DC maturity. Notably, when culturing BMDCs in LEC conditioned media, they assumed an immature phenotype, reminiscent of the DC phenotype in the inflamed skin of K14-VEGFC mice. To our knowledge, this is the first time that LEC-derived factors have been found to directly impact upon DC maturity. Furthermore, LEC-CM also significantly altered DC cytokine profiles, with reduced expression of proinflammatory IL-6 and TNF- $\alpha$ following stimulation with IFN- $\gamma$ and simultaneous upregulation of anti-inflammatory IL-10. Notably, secretion of IL-10 by DCs drives the development of TGF-ß- and IL-10-secreting Tregs, providing a positive feedback loop for its induction [47, 48]. LEC-modulated DCs with an increased expression of IL-10 would thus significantly contribute to an immuneinhibitory microenvironment in K14-VEGFC mice. In addition to IL-10, LEC-CM also strongly primed DC for the expression of CCL2. CCL2 together with its receptor CCR2 is involved in the migration of various immune cells, such as monocytes and macrophages [49], effector T-cells [50] but also Tregs [51]. This may be an additional mechanism whereby increased numbers of Tregs are recruited to the inflamed dermis in K14-VEGFC mice. Furthermore, exposure of splenic T-cells to recombinant CCL2 decreased their ability to produce IFN- $\gamma$ [52] suggesting CCL2 may also inhibit effector T-cells directly.

One potential class of molecules with powerful DC modulatory capabilities are prostaglandins [53, 54]. Blockade of LEC prostaglandin synthesis using celecoxib reduced the anti-inflammatory effects of LEC-CM by reducing DC IL-10 and CCL2 expression, and partially restoring CD40 expression. To further elucidate the mechanisms underlying prostaglandin- 
mediated alterations in DC maturation, we analysed the relative expression of two of the key prostaglandin synthase enzymes, prostacyclin synthase (PTGIS) and prostaglandin E synthase (PGES). In vitro, under inflammatory conditions, LECs upregulated PTGIS while $P G E S$ was downregulated. This finding was supported with inflamed LECs significantly upregulating prostacyclin production. Prostacyclin limited inflammation in in vivo models of viral infection and allergic responses [55-57]. More recently, it has been shown that prostacyclin analogues decreased proinflammatory cytokine secretion (including IL-6 and IL-1ß), upregulated IL-10 production and decreased co-stimulatory and MHCII expression on DC [53], similar to the effects observed here. Conversely, $\mathrm{PGE}_{2}$ is largely considered pro-inflammatory, with $\mathrm{PGES}^{-1-}$ mice exhibiting decreased dermal inflammatory responses and reduced disease severity in a model of rheumatoid arthritis $[58,59]$. With regards to $\mathrm{DC}$ function, $\mathrm{PGE}_{2}$ enhanced co-stimulatory molecule and MHCII expression, induced proinflammatory cytokine secretion [54], and has been shown to augment antigen-specific CD4+ and CD8+ T-cell proliferation [60]. Thus, we believe that a shift towards the generation of anti-inflammatory prostacyclin, together with a decrease in pro-inflammatory $\mathrm{PGE}_{2}$ plays a major role in the attenuation of dermal inflammation by the lymphatic endothelium.

In vivo, COX-2 was surprisingly not upregulated in the inflamed skin of K14-VEGFC mice compared to WT mice. On the other hand, these mice expressed higher levels of PTGIS, while PGES expression was equivalent between the two genotypes. Functional coupling of PGES to COX-2 in preference to COX-1 [61-64] and preferential selectivity of PTGIS to COX-1 [65-68] may add an additional level of regulation to prostaglandin synthesis. Low levels of COX-2 may reduce PGES activity, while a concomitant relative increase in PTGIS activity would allow anti-inflammatory prostacyclin synthesis to dominate. Future studies using a lymphatic specific knockout of PGES or PTGIS would help to dissect the contribution of this mechanism to the regulatory activity of LEC with regard to DC phenotype and inflammation.

Collectively, this study highlights that in addition to enhancing lymphatic drainage by increasing the expansion of lymphatic vessels [5, 69, 70], VEGF-C-induced LECs also possess immune modulating properties that act to reduce inflammation. We have identified LEC-derived prostaglandins as a negative modulator of DC maturation and anti-inflammatory cytokine production in the skin. This effect may be compounded by increased LECderived TGF- $\beta 1$ production (Figure 6). As a result, DC maturation and $\mathrm{CD} 8+\mathrm{T}$-cell activation are inhibited under inflammatory conditions in VEGF-C overexpressing mice, whereas Tregs are elevated. LEC-mediated immunological changes therefore may further impact positively upon the resolution of inflammation. Together, these findings reveal an unanticipated role of the lymphatic endothelium in dampening inflammation via distinct molecular and cellular mechanisms.

\section{MATERIALS AND METHODS}

\section{Mouse model of TPA-induced inflammation}

Chronic dorsal skin inflammation was induced in 6-8 week old hemizygous K14-VEGFC [20] and littermate WT mice with TPA application ( $5 \mu \mathrm{g}$ dissolved in acetone $1 \mathrm{x} /$ week for 5 weeks). Experimentation was undertaken in accordance with protocols approved by the Kantonales Veterinäramt Zürich. Tissue for analysis was harvested two days after the final TPA treatment. Protein was isolated from back skin of known weight as described [5]. VEGF-C and TGF- $\beta 1$ protein was quantified using VEGF-C and TGF- $\beta 1$ ELISA Kits (R\&D Systems), and was normalised to tissue weight and total protein amount within the lysate. Immunofluorescence stainings were performed using standard techniques as described in the Supplementary Methods. Stained sections were examined on an Axioscope Mot Plus microscope (Carl Zeiss) equipped with an Axiocam MRc camera (Carl Zeiss). Images were acquired using Axio-Vision software Version 4.7.1 (Carl Zeiss). ImageJ was used for image analysis. To quantify immune cell infiltration and the area covered by lymphatic vessels in the skin of mice, ten images/ skin section/mouse at a 20x magnification were taken. Foxp $3+\mathrm{CD} 4+$ cells were quantified by manually counting double positive cells in skin sections from three control and four inflamed mice for each genotype.

\section{Flow cytometric analysis of tissue samples}

Single cell suspensions were prepared from tissues and stained as described in the Supplementary Methods. Antibodies used are listed in Supplementary Methods Table 2. Flow cytometry was performed using a FACS Canto Flow Cytometer (BD) and data was analysed using FlowJo software. The expression levels of activation markers are shown as the median fluorescence intensity (MFI).

\section{In vivo dendritic cell migration}

Inflamed back skin of mice was painted with fluorescein isothiocyanate (FITC - 0.5\%, Thermo Scientific) dissolved in acetone/dibutyl phthalate $(1: 1 \mathrm{vol} / \mathrm{vol}$ - Sigma) as described [71, 72]. Eighteen hours later, inguinal and axillary lymph nodes were harvested, cellularity determined and the proportions of FITC + CD $11 \mathrm{c}+\mathrm{CD} 11 \mathrm{~b}+$ cells were quantified (Schematic shown in Figure 2H) using flow cytometry. 


\section{Quantitative RT- PCR}

RNA was isolated as described in the Supplementary Methods. Gene expression was investigated by quantitative RT-PCR using FastStart Universal SYBR Green Master Mix (Roche), the 7900HT Fast Real-time PCR system (Life Technologies), and quantified using the $2^{-\Delta \Delta \mathrm{Ct}}$ method. Primers (Microsynth) are shown in Supplementary Methods Table 3. All data were normalized to the expression of the reference gene Rplp0.

\section{Generation of LEC-conditioned media}

Human dermal lymphatic endothelial cells [73] were cultured on collagen coated $(50 \mu \mathrm{g} / \mathrm{mL})$ tissue culture plates in EBM (Lonza) + 20\% FBS (Life Technologies), 1x penicillin/streptomycin (Life Technologies), $2 \mathrm{mM}$ L-glutamine (Life Technologies), $25 \mu \mathrm{g} / \mathrm{ml}$ cAMP (SigmaAldrich), and $10 \mu \mathrm{g} / \mathrm{ml}$ hydrocortisone (Sigma-Aldrich), until approximately $80 \%$ confluent. Cells were washed twice with PBS and cultured for 72 hours in 1\% FBS $\mathrm{EBM} \pm 20 \mu \mathrm{M}$ Celecoxib (Sigma). Harvested cell culture supernatants were centrifuged and supernatants stored at $-80^{\circ} \mathrm{C}$.

\section{In vitro dendritic cell assays}

$\mathrm{CD} 11 \mathrm{c}+$ cells (BMDCs) were generated from bone marrow as described in the Supplementary Methods. BMDCs were plated in triplicate per treatment group into U-bottom 96 well plates at $2 \times 10^{5} /$ well and stimulated for 24 hours with IFN- $\gamma(100 \mathrm{ng} / \mathrm{mL})$ or TPA $(20 \mathrm{ng} / \mathrm{mL})$. Recombinant human VEGF-C (R\&D) was used at 500 $\mathrm{ng} / \mathrm{mL}$. When assessing the effects of LEC-CM, BMDCs were cultured in 96 well plate wells in $10 \mu \mathrm{L}$ complete media, $10 \mu \mathrm{L} 1 \%$ FBS EBM and $50 \mu \mathrm{L}$ LEC-CM for FACS analysis. For RNA extraction, $5 \times 10^{6}$ BMDCs were plated into 24 well plates and incubated with complete EBM:LEC-CM (1:1). For transwell migration assays, BMDCs were incubated \pm IFN $-\gamma(100 \mathrm{ng} / \mathrm{mL})$. The following day, $2 \times 10^{4}$ cells were seeded onto 24 -well transwell inserts (pore size $5 \mu \mathrm{m}$, Corning), in triplicates. The medium in the bottom chamber consisted of $1 \%$ FBS EBM and $500 \mathrm{ng} / \mathrm{mL}$ VEGF-C (R\&D) or $100 \mathrm{ng} /$ $\mathrm{mL}$ CCL21 (R\&D). Cells were incubated for 4 hours, the lower chamber medium was removed and the cell number was quantified using flow cytometry and Accucheck counting beads (Invitrogen).

\section{Statistical analyses}

Histological parameters were measured in a blinded fashion. All data are expressed as the mean $\pm \mathrm{SD}$ as stated in the figure legends. Statistical significance was assessed using the two-tailed unpaired Student's $t$ test or Two-way ANOVA with Bonferroni's multiple comparison test as stated in the figure legends. A value of $p<0.05$ was taken to be statistically significant.

\section{ACKNOWLEDGMENTS}

We thank Jeannette Scholl, Sun-Young Yoon, Carlos Ochoa, Peter Camenzind and Catharina Seidel for technical assistance. This work was supported by Swiss National Science Foundation grant 310030B_147087, European Research Council grant LYVICAM and Leducq Foundation Transatlantic Network of Excellence grant Lymph Vessels in Obesity and Cardiovascular Disease 11CVD03 (to M.D.) AJC was supported by an NH\&MRC Early Career Fellowship, CJ Martin GNT 1013705 and by an ETH Zurich fellowship.

\section{CONFLICTS OF INTEREST}

The authors declare no conflicts of interest.

\section{REFERENCES}

1. Dieterich LC, Seidel CD and Detmar M. Lymphatic vessels: new targets for the treatment of inflammatory diseases. Angiogenesis. 2014; 17:359-371.

2. Kim H, Kataru RP and Koh GY. Inflammation-associated lymphangiogenesis: a double-edged sword? J Clin Invest. 2014; 124:936-942.

3. Aebischer D, Iolyeva M and Halin C. The inflammatory response of lymphatic endothelium. Angiogenesis. 2014; 17:383-393.

4. Huggenberger R, Ullmann S, Proulx ST, Pytowski B, Alitalo K and Detmar M. Stimulation of lymphangiogenesis via VEGFR-3 inhibits chronic skin inflammation. Journal of Experimental Medicine. 2010; 207:2255-2269.

5. Huggenberger R, Siddiqui SS, Brander D, Ullmann S, Zimmermann K, Antsiferova M, Werner S, Alitalo K and Detmar M. An important role of lymphatic vessel activation in limiting acute inflammation. Blood. 2011; 117:46674678 .

6. Joukov V, Kumar V, Sorsa T, Arighi E, Weich H, Saksela $\mathrm{O}$ and Alitalo K. A recombinant mutant vascular endothelial growth factor-C that has lost vascular endothelial growth factor receptor-2 binding, activation, and vascular permeability activities. J Biol Chem. 1998; 273:6599-6602.

7. Kajiya K, Sawane M, Huggenberger R and Detmar M. Activation of the VEGFR-3 pathway by VEGF-C attenuates UVB-induced edema formation and skin inflammation by promoting lymphangiogenesis. J Invest Dermatol. 2009; 129:1292-1298.

8. Kataru RP, Jung K, Jang C, Yang H, Schwendener RA, Baik JE, Han SH, Alitalo K and Koh GY. Critical role 
of $\mathrm{CD} 11 \mathrm{~b}+$ macrophages and VEGF in inflammatory lymphangiogenesis, antigen clearance, and inflammation resolution. Blood. 2009; 113:5650-5659.

9. Zhou Q, Guo R, Wood R, Boyce BF, Liang Q, Wang Y-J, Schwarz EM and Xing L. Vascular endothelial growth factor $\mathrm{C}$ attenuates joint damage in chronic inflammatory arthritis by accelerating local lymphatic drainage in mice. Arthritis Rheum. 2011; 63:2318-2328.

10. D'Alessio S, Correale C, Tacconi C, Gandelli A, Pietrogrande G, Vetrano S, Genua M, Arena V, Spinelli A, Peyrin-Biroulet L, Fiocchi C and Danese S. VEGF-Cdependent stimulation of lymphatic function ameliorates experimental inflammatory bowel disease. J Clin Invest. 2014; 124:3863-3878.

11. Jurisic G, Sundberg JP and Detmar M. Blockade of VEGF receptor-3 aggravates inflammatory bowel disease and lymphatic vessel enlargement. Inflamm Bowel Dis. 2013; 19:1983-1989.

12. Zhang Y, Lu Y, Ma L, Cao X, Xiao J, Chen J, Jiao S, Gao Y, Liu C, Duan Z, Li D, He Y, Wei B and Wang H. Activation of vascular endothelial growth factor receptor-3 in macrophages restrains TLR4-NF-kappaB signaling and protects against endotoxin shock. Immunity. 2014; 40:501514.

13. Karaman S, Hollmen M, Robciuc MR, Alitalo A, Nurmi H, Morf B, Buschle D, Alkan HF, Ochsenbein AM, Alitalo K, Wolfrum C and Detmar M. Blockade of VEGF-C and VEGF-D modulates adipose tissue inflammation and improves metabolic parameters under high-fat diet. Mol Metab. 2015; 4:93-105.

14. Rouhani SJ, Eccles JD, Tewalt EF and Engelhard VH. Regulation of T-cell Tolerance by Lymphatic Endothelial Cells. J Clin Cell Immunol. 2014; 5.

15. Cohen JN, Guidi CJ, Tewalt EF, Qiao H, Rouhani SJ, Ruddell A, Farr AG, Tung KS and Engelhard VH. Lymph node-resident lymphatic endothelial cells mediate peripheral tolerance via Aire-independent direct antigen presentation. J Exp Med. 2010; 207:681-688.

16. Tewalt EF, Cohen JN, Rouhani SJ, Guidi CJ, Qiao H, Fahl SP, Conaway MR, Bender TP, Tung KS, Vella AT, Adler AJ, Chen L and Engelhard VH. Lymphatic endothelial cells induce tolerance via PD-L1 and lack of costimulation leading to high-level PD-1 expression on CD8 T cells. Blood. 2012; 120:4772-4782.

17. Hirosue S, Vokali E, Raghavan VR, Rincon-Restrepo M, Lund AW, Corthesy-Henrioud P, Capotosti F, Halin Winter C, Hugues S and Swartz MA. Steady-state antigen scavenging, cross-presentation, and CD8+ T cell priming: a new role for lymphatic endothelial cells. J Immunol. 2014; 192:5002-5011

18. Rouhani SJ, Eccles JD, Riccardi P, Peske JD, Tewalt EF, Cohen JN, Liblau R, Makinen T and Engelhard VH. Roles of lymphatic endothelial cells expressing peripheral tissue antigens in CD4 T-cell tolerance induction. Nat Commun.
2015; 6:6771.

19. Lund Amanda W, Duraes Fernanda V, Hirosue S, Raghavan Vidya R, Nembrini C, Thomas Susan N, Issa A, Hugues $\mathrm{S}$ and Swartz Melody A. VEGF-C Promotes Immune Tolerance in B16 Melanomas and Cross-Presentation of Tumor Antigen by Lymph Node Lymphatics. CellReports. 2012:1-9.

20. Jeltsch M. Hyperplasia of lymphatic vessels in VEGF-C transgenic mice. Science. 1997; 276:1423-1425.

21. Hirakawa S, Brown LF, Kodama S, Paavonen K, Alitalo $\mathrm{K}$ and Detmar M. VEGF-C-induced lymphangiogenesis in sentinel lymph nodes promotes tumor metastasis to distant sites. Blood. 2007; 109:1010-1017.

22. Aldaz CM, Conti CJ, Gimenez IB, Slaga TJ and KleinSzanto AJ. Cutaneous changes during prolonged application of 12-O-tetradecanoylphorbol-13-acetate on mouse skin and residual effects after cessation of treatment. Cancer Res. 1985; 45:2753-2759.

23. Stanley PL, Steiner S, Havens M and Tramposch KM. Mouse skin inflammation induced by multiple topical applications of 12-O-tetradecanoylphorbol-13-acetate. Skin Pharmacol. 1991; 4:262-271.

24. Hvid H, Teige I, Kvist PH, Svensson L and Kemp K. TPA induction leads to a Th17-like response in transgenic K14/ VEGF mice: a novel in vivo screening model of psoriasis. International Immunology. 2008; 20:1097-1106.

25. Alitalo AK, Proulx ST, Karaman S, Aebischer D, Martino S, Jost M, Schneider N, Bry M and Detmar M. VEGF-C and VEGF-D blockade inhibits inflammatory skin carcinogenesis. Cancer Res. 2013; 73:4212-4221.

26. Ohl L, Mohaupt M, Czeloth N, Hintzen G, Kiafard Z, Zwirner J, Blankenstein T, Henning G and Forster R. CCR7 governs skin dendritic cell migration under inflammatory and steady-state conditions. Immunity. 2004; 21:279-288.

27. Jonuleit H, Schmitt E, Schuler G, Knop J and Enk AH. Induction of interleukin 10-producing, nonproliferating CD4(+) T cells with regulatory properties by repetitive stimulation with allogeneic immature human dendritic cells. J Exp Med. 2000; 192:1213-1222.

28. Dhodapkar MV, Steinman RM, Krasovsky J, Munz C and Bhardwaj N. Antigen-specific inhibition of effector T cell function in humans after injection of immature dendritic cells. J Exp Med. 2001; 193:233-238.

29. Yamaguchi $Y$, Tsumura $H$, Miwa $M$ and Inaba $K$. Contrasting effects of TGF-beta 1 and TNF-alpha on the development of dendritic cells from progenitors in mouse bone marrow. Stem Cells. 1997; 15:144-153.

30. Strobl H and Knapp W. TGF-betal regulation of dendritic cells. Microbes Infect. 1999; 1:1283-1290.

31. Chen W, Jin W, Hardegen N, Lei KJ, Li L, Marinos N, McGrady $G$ and Wahl SM. Conversion of peripheral $\mathrm{CD} 4+\mathrm{CD} 25$ - naive $\mathrm{T}$ cells to $\mathrm{CD} 4+\mathrm{CD} 25+$ regulatory $\mathrm{T}$ cells by TGF-beta induction of transcription factor Foxp3. J Exp Med. 2003; 198:1875-1886. 
32. Marie JC, Letterio JJ, Gavin M and Rudensky AY. TGFbeta1 maintains suppressor function and Foxp3 expression in CD4+CD25+ regulatory T cells. J Exp Med. 2005; 201:1061-1067.

33. Chen W, Jin W and Wahl SM. Engagement of cytotoxic $\mathrm{T}$ lymphocyte-associated antigen 4 (CTLA-4) induces transforming growth factor beta (TGF-beta) production by murine CD4(+) T cells. J Exp Med. 1998; 188:1849-1857.

34. Gorelik L, Constant S and Flavell RA. Mechanism of transforming growth factor beta-induced inhibition of $\mathrm{T}$ helper type 1 differentiation. J Exp Med. 2002; 195:14991505.

35. Kalyan Kumar G, Dhamotharan R, Kulkarni NM, Mahat MY, Gunasekaran J and Ashfaque M. Embelin reduces cutaneous TNF-alpha level and ameliorates skin edema in acute and chronic model of skin inflammation in mice. Eur J Pharmacol. 2011; 662:63-69.

36. Teige I, Hvid H, Svensson L, Kvist PH and Kemp K. Regulatory $\mathrm{T}$ cells control VEGF-dependent skin inflammation. J Invest Dermatol. 2009; 129:1437-1445.

37. Lewis JG and Adams DO. Early inflammatory changes in the skin of SENCAR and C57BL/6 mice following exposure to 12-O-tetradecanoylphorbol-13-acetate. Carcinogenesis. 1987; 8:889-898.

38. Forster R, Schubel A, Breitfeld D, Kremmer E, RennerMuller I, Wolf E and Lipp M. CCR7 coordinates the primary immune response by establishing functional microenvironments in secondary lymphoid organs. Cell. 1999; 99:23-33.

39. Sakaguchi S, Wing K, Onishi Y, Prieto-Martin P and Yamaguchi T. Regulatory T cells: how do they suppress immune responses? Int Immunol. 2009; 21:1105-1111.

40. Gorelik L and Flavell RA. Transforming growth factor-beta in T-cell biology. Nat Rev Immunol. 2002; 2:46-53.

41. Bonham CA, Lu L, Banas RA, Fontes P, Rao AS, Starzl TE, Zeevi A and Thomson AW. TGF-beta 1 pretreatment impairs the allostimulatory function of human bone marrow-derived antigen-presenting cells for both naive and primed T cells. Transpl Immunol. 1996; 4:186-191.

42. Ghiringhelli F, Puig PE, Roux S, Parcellier A, Schmitt E, Solary E, Kroemer G, Martin F, Chauffert B and Zitvogel L. Tumor cells convert immature myeloid dendritic cells into TGF-beta-secreting cells inducing CD4+CD25+ regulatory T cell proliferation. J Exp Med. 2005; 202:919-929.

43. Fantini MC, Becker C, Monteleone G, Pallone F, Galle PR and Neurath MF. Cutting edge: TGF-beta induces a regulatory phenotype in $\mathrm{CD} 4+\mathrm{CD} 25-\mathrm{T}$ cells through Foxp3 induction and down-regulation of Smad7. J Immunol. 2004; 172:5149-5153.

44. Gabrilovich D, Ishida T, Oyama T, Ran S, Kravtsov V, Nadaf S and Carbone DP. Vascular endothelial growth factor inhibits the development of dendritic cells and dramatically affects the differentiation of multiple hematopoietic lineages in vivo. Blood. 1998; 92:41504166.

45. Gabrilovich DI, Chen HL, Girgis KR, Cunningham HT, Meny GM, Nadaf S, Kavanaugh D and Carbone DP. Production of vascular endothelial growth factor by human tumors inhibits the functional maturation of dendritic cells. Nat Med. 1996; 2:1096-1103.

46. Podgrabinska S, Kamalu O, Mayer L, Shimaoka M, Snoeck H, Randolph GJ and Skobe M. Inflamed lymphatic endothelium suppresses dendritic cell maturation and function via Mac-1/ICAM-1-dependent mechanism. J Immunol. 2009; 183:1767-1779.

47. Groux H, O'Garra A, Bigler M, Rouleau M, Antonenko $\mathrm{S}$, de Vries JE and Roncarolo MG. A CD4+ T-cell subset inhibits antigen-specific T-cell responses and prevents colitis. Nature. 1997; 389:737-742.

48. Barrat FJ, Cua DJ, Boonstra A, Richards DF, Crain C, Savelkoul HF, de Waal-Malefyt R, Coffman RL, Hawrylowicz CM and O'Garra A. In vitro generation of interleukin 10-producing regulatory $\mathrm{CD} 4(+) \mathrm{T}$ cells is induced by immunosuppressive drugs and inhibited by $\mathrm{T}$ helper type 1 (Th1)- and Th2-inducing cytokines. J Exp Med. 2002; 195:603-616.

49. Wang Y, Cui L, Gonsiorek W, Min SH, Anilkumar G, Rosenblum S, Kozlowski J, Lundell D, Fine JS and Grant EP. CCR2 and CXCR4 regulate peripheral blood monocyte pharmacodynamics and link to efficacy in experimental autoimmune encephalomyelitis. J Inflamm (Lond). 2009; $6: 32$.

50. Shulman Z, Cohen SJ, Roediger B, Kalchenko V, Jain R, Grabovsky V, Klein E, Shinder V, Stoler-Barak L, Feigelson SW, Meshel T, Nurmi SM, Goldstein I, Hartley O, Gahmberg CG, Etzioni A, et al. Transendothelial migration of lymphocytes mediated by intraendothelial vesicle stores rather than by extracellular chemokine depots. Nat Immunol. 2012; 13:67-76.

51. Jordan JT, Sun W, Hussain SF, DeAngulo G, Prabhu SS and Heimberger AB. Preferential migration of regulatory $\mathrm{T}$ cells mediated by glioma-secreted chemokines can be blocked with chemotherapy. Cancer Immunol Immunother. 2008; 57:123-131.

52. Vitiello PF, Shainheit MG, Allison EM, Adler EP and Kurt RA. Impact of tumor-derived CCL2 on T cell effector function. Immunol Lett. 2004; 91:239-245.

53. Zhou W, Hashimoto K, Goleniewska K, O’Neal JF, Ji S, Blackwell TS, Fitzgerald GA, Egan KM, Geraci MW and Peebles RS, Jr. Prostaglandin I2 analogs inhibit proinflammatory cytokine production and $\mathrm{T}$ cell stimulatory function of dendritic cells. J Immunol. 2007; 178:702-710.

54. Khayrullina $\mathrm{T}$, Yen $\mathrm{JH}$, Jing $\mathrm{H}$ and Ganea D. In vitro differentiation of dendritic cells in the presence of prostaglandin E2 alters the IL-12/IL-23 balance and promotes differentiation of Th17 cells. J Immunol. 2008; 181:721-735. 
55. Hashimoto K, Graham BS, Geraci MW, FitzGerald GA, Egan K, Zhou W, Goleniewska K, O’Neal JF, Morrow JD, Durbin RK, Wright PF, Collins RD, Suzutani T and Peebles RS, Jr. Signaling through the prostaglandin I 2 receptor IP protects against respiratory syncytial virus-induced illness. J Virol. 2004; 78:10303-10309.

56. Nagao K, Tanaka H, Komai M, Masuda T, Narumiya S and Nagai H. Role of prostaglandin I2 in airway remodeling induced by repeated allergen challenge in mice. Am J Respir Cell Mol Biol. 2003; 29:314-320.

57. Takahashi Y, Tokuoka S, Masuda T, Hirano Y, Nagao M, Tanaka $\mathrm{H}$, Inagaki $\mathrm{N}$, Narumiya $\mathrm{S}$ and Nagai $\mathrm{H}$. Augmentation of allergic inflammation in prostanoid IP receptor deficient mice. Br J Pharmacol. 2002; 137:315322.

58. Trebino CE, Stock JL, Gibbons CP, Naiman BM, Wachtmann TS, Umland JP, Pandher K, Lapointe JM, Saha S, Roach ML, Carter D, Thomas NA, Durtschi BA, McNeish JD, Hambor JE, Jakobsson PJ, et al. Impaired inflammatory and pain responses in mice lacking an inducible prostaglandin E synthase. Proc Natl Acad Sci U S A. 2003; 100:9044-9049.

59. Kamei D, Yamakawa K, Takegoshi Y, Mikami-Nakanishi M, Nakatani Y, Oh-Ishi S, Yasui H, Azuma Y, Hirasawa N, Ohuchi K, Kawaguchi H, Ishikawa Y, Ishii T, Uematsu S, Akira S, Murakami M, et al. Reduced pain hypersensitivity and inflammation in mice lacking microsomal prostaglandin e synthase-1. J Biol Chem. 2004; 279:33684-33695.

60. Krause P, Bruckner M, Uermosi C, Singer E, Groettrup $\mathrm{M}$ and Legler DF. Prostaglandin E(2) enhances T-cell proliferation by inducing the costimulatory molecules OX40L, CD70, and 4-1BBL on dendritic cells. Blood. 2009; 113:2451-2460.

61. Murakami M, Naraba H, Tanioka T, Semmyo N, Nakatani Y, Kojima F, Ikeda T, Fueki M, Ueno A, Oh S and Kudo I. Regulation of prostaglandin E2 biosynthesis by inducible membrane-associated prostaglandin E2 synthase that acts in concert with cyclooxygenase-2. J Biol Chem. 2000; 275:32783-32792.

62. Naraba H, Murakami M, Matsumoto H, Shimbara S, Ueno A, Kudo I and Oh-ishi S. Segregated coupling of phospholipases A2, cyclooxygenases, and terminal prostanoid synthases in different phases of prostanoid biosynthesis in rat peritoneal macrophages. J Immunol. 1998; 160:2974-2982.

63. Brock TG, McNish RW and Peters-Golden M. Arachidonic acid is preferentially metabolized by cyclooxygenase-2 to prostacyclin and prostaglandin E2. J Biol Chem. 1999; 274:11660-11666.
64. Li S, Wang Y, Matsumura K, Ballou LR, Morham SG and Blatteis CM. The febrile response to lipopolysaccharide is blocked in cyclooxygenase-2(-/-), but not in cyclooxygenase-1(-/-) mice. Brain Res. 1999; 825:86-94.

65. Kirkby NS, Lundberg MH, Harrington LS, Leadbeater PD, Milne GL, Potter CM, Al-Yamani M, Adeyemi O, Warner TD and Mitchell JA. Cyclooxygenase-1, not cyclooxygenase-2, is responsible for physiological production of prostacyclin in the cardiovascular system. Proc Natl Acad Sci U S A. 2012; 109:17597-17602.

66. Mitchell JA, Lucas R, Vojnovic I, Hasan K, Pepper JR and Warner TD. Stronger inhibition by nonsteroid antiinflammatory drugs of cyclooxygenase- 1 in endothelial cells than platelets offers an explanation for increased risk of thrombotic events. FASEB J. 2006; 20:2468-2475.

67. Liu B, Luo W, Zhang Y, Li H, Zhu N, Huang D and Zhou Y. Involvement of cyclo-oxygenase-1-mediated prostacyclin synthesis in the vasoconstrictor activity evoked by ACh in mouse arteries. Exp Physiol. 2012; 97:277-289.

68. Liu B, Zhang Y, Zhu N, Li H, Luo W and Zhou Y. A vasoconstrictor role for cyclooxygenase-1-mediated prostacyclin synthesis in mouse renal arteries. Am J Physiol Renal Physiol. 2013; 305:F1315-1322.

69. Proulx ST, Luciani P, Derzsi S, Rinderknecht M, Mumprecht V, Leroux JC and Detmar M. Quantitative imaging of lymphatic function with liposomal indocyanine green. Cancer Res. 2010; 70:7053-7062.

70. Harrell MI, Iritani BM and Ruddell A. Tumor-induced sentinel lymph node lymphangiogenesis and increased lymph flow precede melanoma metastasis. Am J Pathol. 2007; 170:774-786.

71. Aebischer D, Willrodt AH and Halin C. Oxazolone-induced contact hypersensitivity reduces lymphatic drainage but enhances the induction of adaptive immunity. PLoS ONE. 2014; 9:e99297.

72. Vigl B, Aebischer D, Nitschke M, Iolyeva M, Rothlin T, Antsiferova $\mathrm{O}$ and Halin $\mathrm{C}$. Tissue inflammation modulates gene expression of lymphatic endothelial cells and dendritic cell migration in a stimulus-dependent manner. Blood. 2011; 118:205-215.

73. Hirakawa S, Hong YK, Harvey N, Schacht V, Matsuda $\mathrm{K}$, Libermann $\mathrm{T}$ and Detmar M. Identification of vascular lineage-specific genes by transcriptional profiling of isolated blood vascular and lymphatic endothelial cells. Am J Pathol. 2003; 162:575-586. 